\title{
ASSOCIATION OF THYROID DYSFUNCTION WITH FEMALE INFERTILITY
}

\author{
Muhammad Arshad ${ }^{1}$, Shafaq Naz ${ }^{1}$, Shah Zeb ${ }^{1}$.
}

1. Naseer Teaching Hospital Peshawar. (NTH)

\begin{abstract}
Objective:

To find association of hyperthyroidism with female infertility.

To find association of hypothyroidism with female infertility.

Cross sectional study design was conducted.
\end{abstract}

\section{Place and Duration of Study:}

Random Infertile females were selected amongst the patients who attended the outpatient department of Naseer Teaching Hospital (NTH) Peshawar from June 2013 to June 2014.

\section{Material and Methods:}

This study was done on hundred infertile females. They were selected randomly from amongst the patients who attended the outpatient department of Naseer Teaching Hospital Peshawar. A detailed history of patients was recorded on a proper questionnaire. This included information about patient age, weight, marriage duration, menstrual history, drug history, any symptoms and signs of thyroid disorder etc. Peripheral venous blood samples were collected aseptically with patient written consent and tested for thyroid function.

\section{Results:}

Hundred primary infertile patients were included in the study. Out of these 100 patients, TSH was raised in 14(14\%) of infertile females while 27(27\%) infertile females had low TSH levels. Based on the levels of T3 and T4, all the 41(41\%) thyroid dysfunction cases were subdivided further into overt and subclinical thyroid dysfunction. Our study showed that $5 \%$ were suffering from overt hypothyroidism, $11 \%$ from subclinical hypothyroidism, $7 \%$ overt hyperthyroidism while $18 \%$ were suffering from subclinical hyperthyroidism.

\section{Conclusion:}

This study shows that subclinical thyroid dysfunction is more common than overt thyroid dysfunction in infertile females. Therefore, measurement of serum T3, T4 and TSH levels should be included in the workup of infertility. The patient can revert back to the fertile state with appropriate treatment.

Key Words: Association, thyroid dysfunction, infertility.

Correspondence:

Dr. Muhammad Arshad, Associate Professor of Medicine, Naseer Teaching Hospital

Contact: 0333-9198254, E mail: arshad_physician@yahoo.com

https://doi.org/10.37762/jgmds.1-1.70 


\section{INTRODUCTION}

Failure to conceive after regular sexual intercourse for one year without using methods of contraception and any known reproductive disease is defined as infertility ${ }^{1}$.

There are two types of infertility, i.e. primary infertility and secondary infertility.Primary infertility is one which occurs in couples who have not conceived previously while secondary infertility is the type which occurs in couples who have conceived previously but are not able to conceive again ${ }^{2}$.

There are many causes of female infertility including hypothalamic-pituitary-ovarian (HPO) axis dysfunction, disorders of ovulation and factors relating to endometrium ${ }^{1,2}$.

In all the infertile cases, $37 \%$ are caused by female infertility ${ }^{3}$.Infertility in females is common and can cause serious economic, medical, psychological and social problems ${ }^{2}$.

Both, hyperthyroidism and hypothyroidism are one of the most common endocrine causes of female infertility ${ }^{3,4}$.

Thyroid-stimulating hormone (TSH) released by the anterior pituitary gland stimulates thyroid gland to secrete thyroid hormones thyroxin (T4) and tri iodothyronine (T3) 5 .

In females thyroid disorders are four to five times more common than men. Thyroid dysfunctions, both hyperthyroidism and hypothyroidism, have important effects on estrogen metabolism, menstrual function and fertility.

Prolactin level is increased in hypothyroidism which has negative effect on ovulation. There is an increased risk of cysts formations in ovaries or polycystic ovaries in hypothyroidism which can lead to infertility ${ }^{6}$.

Thyroid hormones effect menstruation directly by impact on ovaries andindirectly through influence on Sex Hormone-Binding-Globulin (SHBG) Prolactin(PRL) and Gonadotropin releasing hormone $(\mathrm{GnRH})$ secretion. Menstrual abnormalities can be restored by treating thyroid dysfunctions which will lead to improvement in fertility ${ }^{7}$.

Thyrotoxicosis is a common and treatable cause of menstrual abnormalities. As thyroid hormones have significant and reversible effect on female fertility, so it is very important to assess thyroid status of an infertile female ${ }^{8}$.

Thyroid hormones measurement is considered an important step of infertility workup in women ${ }^{9}$. The aims of the study were to find the prevalence of thyroid disorders in female infertility after exclusion of tubal and male factor infertility.

\section{MATERIAL AND METHODS}

This study was done on hundred infertile females. They were selected randomly from amongst the patients who attended the outpatient department of Naseer Teaching Hospital Peshawar.

This study included infertile females between the ages of 20-30 years with duration of marriage not less than one year. Infertile females with any congenital anomaly of the urogenital tract, any pathology in tubes, ovary or uterus, any male infertility factor and any history of thyroid disorder, past thyroid surgery or those on thyroid medications were excluded. A detailed history of patients was recorded on a proper questionnaire. This included information about patient age, 
weight, marriage duration, past medical and surgical history, drug history, menstrual history, any symptoms and signs of thyroid dysfunction etc. Peripheral venous blood samples were collected aseptically with patient written consent and assayed for thyroid function tests.

\section{RESULTS}

This study includes 100 infertile females as cases.

Most of the patients were in the age group of $23-27$ years and the average duration of infertility was 6 years or less. As shown in Table 1, serum T3, T4 levels were high significantly in infertile women. Serum TSH levels were low in infertile women. Percentage prevalence of thyroid dysfunction in primary infertile females is summarized in Table 2. Out of 100 primary infertile patients included in the study, 14(14\%) infertile women had high TSH $(>5.45 \mu \mathrm{lU} / \mathrm{ml})$ and $27(27$ $\%)$ infertile women had low TSH levels $(<0.28 \mu \mathrm{lU} / \mathrm{ml})$. Based on the levels of T3 and T4, all the $41(41 \%)$ thyroid dysfunction cases were subdivided further into overt and subclinical thyroid dysfunction. Our study showed that $5 \%$ were suffering from overt hypothyroidism, $11 \%$ from subclinical hypothyroidism, $7 \%$ overt hyperthyroidism while $18 \%$ were suffering from subclinical hyperthyroidism.

Table 1: Thyroid profile results

\begin{tabular}{|c|l|}
\hline Parameter & Cases (infertile women) $(\mathrm{n}=100)$ \\
\hline $\mathrm{T} 3(\mathrm{ng} / \mathrm{ml})$ & $1.6 \pm 0.57$ \\
\hline $\mathrm{T} 4(\mu \mathrm{g} / \mathrm{dl})$ & $9.7 \pm 2.86$ \\
\hline $\mathrm{TSH}(\mu \mathrm{lU} / \mathrm{ml})$ & $1.5 \pm 1.66$ \\
\hline
\end{tabular}

All the values were expressed as Mean \pm S.D,

Table 2: Percentage prevalence of thyroid dysfunction in infertile group

\begin{tabular}{|l|c|c|}
\hline \multicolumn{1}{|c|}{ Type of the cases } & No. of cases & Percentage \\
\hline Overt hypothyroidism & 4 & 4.0 \\
\hline Subclinical hypothyroidism & 12 & 12.0 \\
\hline Overt hyperthyroidism & 6 & 6.0 \\
\hline Subclinical hyperthyroidism & 20 & 20.0 \\
\hline Euthyroidism & 58 & 58.0 \\
\hline
\end{tabular}




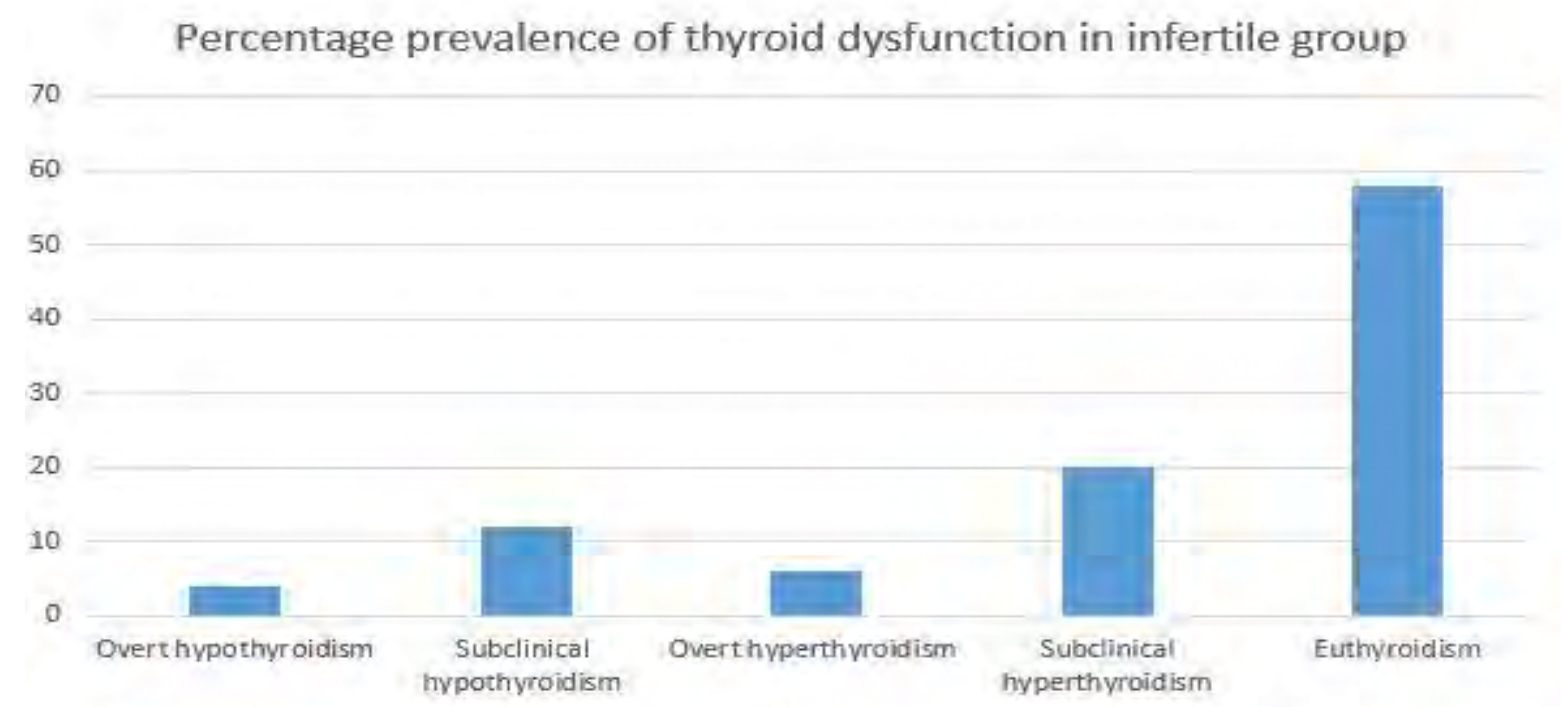

\section{DISCUSSION}

Female infertility occurs in about $37 \%$ of all infertile couples and ovulatory disorders account for more than half of these ${ }^{10}$. Thyroid hormones have profound effects on reproduction and pregnancy. Both subclinical hyperthyroidism and subclinical hypothyroidism are increasingly being recognized as having significant health implications ${ }^{11}$.

In the present study, there is statistically significant increase in mean serum T3 and T4 and decrease in TSH levels in infertile women when compared to controls. Hyperthyroidism (26\%) was more prevalent than hypothyroidism (16\%) in our study. This is in accordance with the report of Singh et al ${ }^{12}$.

The prevalence of thyroid dysfunction in infertile women was found to be $33.3 \%$ in a study by Rahman et al ${ }^{13}$ and $23 \%$ by Sharma et al ${ }^{14}$.

In our study, thyroid dysfunction was present in $42 \%$ of the infertile women. It is obvious from the observation that fertility of female reproductive system is hampered by altered thyroid hormone levels. Majority of the patients were in euthyroid state which may be due to other cause of infertility. The prevalence of hypothyroidism in the reproductive age group and defined as a abnormally elevated TSH concentration, ranges from 2-4 $\%{ }^{14,15}$ which is found to be $6.7 \%$ by Rahman et $\mathrm{al}^{14}, 8 \%$ by Goswami et al ${ }^{17}$ and $20 \%$ by Sharma et al ${ }^{15}$ while in our study this prevalence was $16 \%$. Subclinical hypothyroidism is associated with ovulatory dysfunction ${ }^{19}$. Previous studies revealed variable data on prevalence of subclinical hypothyroidism in infertility, $25 \%$ by Bals Pratsch et al ${ }^{18}$ and $4.6 \%$ by Grassi et al ${ }^{19}$ In our study, $12 \%$ infertile women were suffering from subclinical hypothyroidism. Also subclinical hypothyroidism was more common than overt hypothyroidism in the present study, which is in accordance with Verma et al ${ }^{20}$. The prevalence of hyperthyroidism was about $23 \%$ by Singh et al ${ }^{13}, 8 \%$ in the study by Goswami et al 18 and $5.8 \%$ by Joshi et al ${ }^{21}$. 
Thyroid dysfunction is a common cause of infertility which can be easily managed by correcting the appropriate levels of thyroid hormones. The decision to initiate thyroid correction therapy in subclinical thyroid dysfunction at early stage is justified in infertile women. Our data also indicate that variations in TSH levels in the narrower range should not be ignored in infertile women who are otherwise asymptomatic for clinical hyperthyroidism. This group of infertile women, if only carefully diagnosed and treated for hyperthyroidism, can benefit a lot rather than going for unnecessary battery of hormone assays and costly invasive procedures. For better management of infertility case, we should plan further studies with the large sample size and investigate the beneficial effect of drug treatment by long-term follow-up, which are necessary to validate the variation in T3, T4 and TSH levels. In addition to thyroid profile other endocrine hormones like prolactin should be considered in infertility.

\section{CONCLUSION}

This study shows that overt thyroid dysfunction is less prevalent than subclinical thyroid dysfunction in infertile females. It seems that hyperthyroidism is a dominant thyroid dysfunction in infertile females. These disorders may cause menstrual abnormalities and anovulatory cycles resulting in infertility. Therefore, measurement of serum T3, T4 and TSH levels should be included in the workup of infertility so that the patient can be diagnosed and treated accordingly with medications and can revert back to the fertile state.

\section{REFERNCES}

1.Ash Monga \& Stephen Dobbs. Gynaecology by Ten Teachers. Hodder Arnold,London 2011 ; 85-86

2.Nasima Akther, Sufi Ahammad Hassan. Sub-clinical hypothyroidism and Hyperprolactinaemia in infertile women. The internal journal of Endocrinology. 2009 ; 5 (1) : 1540-2606.

3. David Unuane, Herman Tournaye, Kris Poppe. Endocrine disorders \&female Infertility. Best practice and Research Clinical Endocrinology \& Metabolism. December 2011; 25 (6): 861-73.

4. Jones EE. Hyperprolactinaemia and female infertility. J Reprod Med. 1989 Feb; 34 (2);117-26.

5. William J Marshall, Stephen K Bangert. Clinical Chemistry. Mosby Elsevier, Philadelphia. 2008 : $134,175$.

6. Dilruba Rehman, Parveen Fatima and Jesmine Banu. Thyroid Disorders In Female Subfertility. JCMCTA 2008; 19 (2): 46-50.

7. Stephen J. Mcphee. Maxine A Papadakis. Current Medical diagnosis and treatment. Paul A. Fitzgerald. Lagne Megraw Hill. 2011 : 1059-61.

8. Trokoudes, Krinos Ma; Skordis, etall. Infertility and Thyroid disorders. Current opinion in Obstetrics and Gynecology August 2006 ; 18 (4) : 446-51.

9. Goswami, Binita, Chatterjee, etall. Correlation of Prolactin and Thyroid Hormone Concentration with Menstrual patterns in Infertile Women. J Reprod Infertil 2009 ; 10 (3) : 207-12. 
10. Unuane D, Tournave H, Velkeniers B, Poppe K., Endocrine disorders \& female infertility. Best Practice \& Research Clinical Endocrinology \& Metabolism2011;25(6) : 861-873.

11. Nananda F, Surks MI, Daniels GH., Subclinical thyroid disease. JAMA2004; 291:239-243.

12. Singh L, Agarwal C, Chaudhary CR, Mehra P, Khare R., Thyroid profile in infertile women. Ind J Gynae and Obst1990;37(12):248-253.

13. Rahman D, Fatima P, Banu J., Thyroid disorders in female subfertility. JCMCTA 2008;19(2):46-50.

14. Sharma UR, Parmar C: Thyroid profile in infertile women and menstrua dysfunction. Source Indian Medical Gazette, updated 2007,

15.Wang C, Crapo LM., The epidemiology of thyroid disease and implications for screening. Endocrinol Metab Clin North Am1997;26(1):189-218.

16. Bjoro T, Holmen J, Kruger O, Midthjell K, Hunstad K, Schreiner T et al., Prevalence of thyroid disease, thyroid dysfunction and thyroid peroxidase antibodies in a large unselected population. The Health Study of Nord-Trondelag (HUNT). Eur J Endocrinol 2000;143(5):639-647.

17. Goswami B, Patel S, Chatterjee M, Koner B C, Saxena A., Correlation of prolactin and thyroid hormone concentration with menstrual patterns in infertile women. J Reprod Infertil2009;10(3):207-212.

18. Lincon SR, Ke RW, Kutteh WH. Screening for hypothyroidism in infertile women. Journal of Reprod Med1999;44:455-457.

19. Bals Pratsch M, De Geyter C, Muller T, Frie Ling U, Lerchi A, Pirke KM et al., Episodic variations of prolactin, thyroid stimulating hormone, luteinizing hormone, melatonin and cortisol in infertile women with subclinical hypothyroidism. Human Reproduction1997;12(5): 896-904.

20. Verma I, Sood R, Juneja S, Kaur S., Prevalence of hypothyroidism in infertile women and evaluation of response of treatment for hypothyroidism in infertility. International journal of applied basic medical research2012;2(1):12-19.

21. Joshi JV, Bhandarkar SD, Chadha M, Balaih D, and Shah R., Menstrual irregularities and lactation failure may precede thyroid dysfunction or goiter. J Postgrad Med1993;39:137-141.

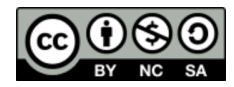

LICENSE: JGMDS publishes its articles under a Creative Commons Attribution Non-Commercial Share-Alike license (CC-BY-NC-SA 4.0). COPYRIGHTS: Authors retain the rights without any restrictions to freely download, print, share and disseminate the article for any lawful purpose. It includes scholarly networks such as Research Gate, Google Scholar, LinkedIn, Academia.edu, Twitter, and other academic or professional networking sites. 